\title{
A Novel Binder-Free Sulfur/Polypyrrole Cathode for Lithium/Sulfur Batteries
}

\author{
Li Wang ${ }^{1}$, Zichuan $\mathrm{Yi}^{4,5,6}$, Xin Wang ${ }^{1,3, *}$, Yongguang Zhang ${ }^{2, *}$, Mingliang Jin ${ }^{1,3}$, Guofu Zhou ${ }^{1,5,6}$ \\ ${ }^{1}$ Institute of Electronic Paper Displays, South China Academy of Advanced Optoelectronics, South \\ China Normal University, Guangzhou, Guangdong Province, China \\ ${ }^{2}$ Synergy Innovation Institute of GDUT, Heyuan, Guangdong Province, China \\ ${ }^{3}$ International Academy of Optoelectronics at Zhaoqing, South China Normal University, National \\ High-Tech Zone, Zhaoqing, Guangdong Province, China \\ ${ }^{4}$ University of Electronic Science and Technology of China, Zhongshan Insititute, Zhongshan 528402, \\ China \\ ${ }^{5}$ Shenzhen Guohua Optoelectronics Tech. Co. Ltd., Shenzhen 518110, China \\ ${ }^{6}$ Academy of Shenzhen Guohua Optoelectronics, Shenzhen 518110, China \\ *E-mail: wangxin@scnu.edu.cn, zyg1984723@hotmail.com
}

doi: $10.20964 / 2017.06 .82$

Received: 30 November 2016 / Accepted: 14 April 2017 / Published: 12 May 2017

\begin{abstract}
A novel type cathode for lithium/sulfur batteries is introduced based on polypyrrole nanowires on a $\mathrm{Ni}$ foil without any binder. Herein, a facile two-step approach is developed in this paper for the fabrication of novel three-dimensional nanoarchitectures of composite. Polypyrrole nanowires are directly synthesized on the Ni current collector. PPy on Ni foil is utilized as the flexible substrate for the infiltration of S via heat-treatment. The S/PPy binary composite electrode delivers a large reversible capacity of $1166 \mathrm{mAh} \mathrm{g}^{-1}$ with appealing cycling stability (57\% capacity retained after 100 cycles). The electrochemical results show that PPy nanowire directly growing on the Ni foil current collectorcould offer both an electron-conductive path and a stable substrate for the sulfur electrode. Besides, PPy also has strong adhesion to the surface of $\mathrm{Ni}$ foil and absorbs polysulfides into its porous structure.
\end{abstract}

Keywords: Binder-free, Electropolymerized, sulfur/polypyrrole composite, sulfur cathode, lithium/sulfur battery.

\section{$\underline{\text { FULL TEXT }}$}

(C) 2017 The Authors. Published by ESG (www.electrochemsci.org). This article is an open access article distributed under the terms and conditions of the Creative Commons Attribution license (http://creativecommons.org/licenses/by/4.0/). 